\title{
CORRECTION
}

\section{Correction to: Controlling interfacial mixing zone for microfluidic flow of liquid streams}

\author{
Paritosh Agnihotri ${ }^{1} \cdot$ V. N. $\operatorname{Lad}^{1}$ (1)
}

Published online: 8 January 2019

(c) The Brazilian Society of Mechanical Sciences and Engineering 2019

\author{
Correction to: \\ Journal of the Brazilian Society of Mechanical Sciences \\ and Engineering (2018) 40:301 \\ https://doi.org/10.1007/s40430-018-1203-8
}

The correction and addition are as below.

The figure caption and the sub-parts of Fig. 5 should read as appeared below.

The original article can be found online at https://doi.org/10.1007/ s40430-018-1203-8.

V. N. Lad

vnl@ched.svnit.ac.in; lad.vnl@gmail.com

1 Chemical Engineering Department, Sardar Vallabhbhai

National Institute of Technology - Surat, Ichchhanath, Surat,

Gujarat 395007, India 
(a)

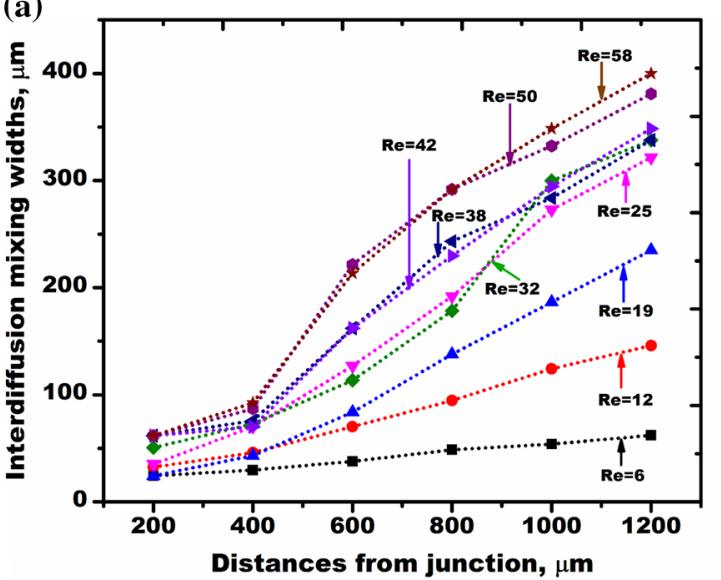

(c)

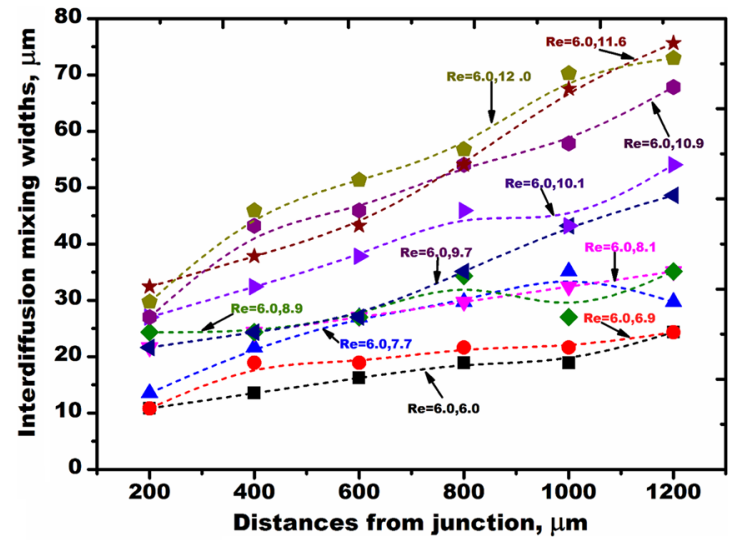

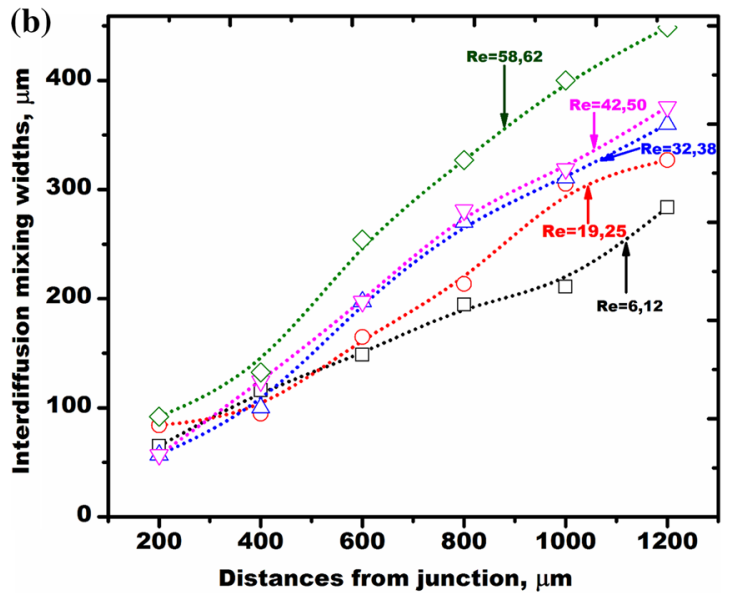

(d)

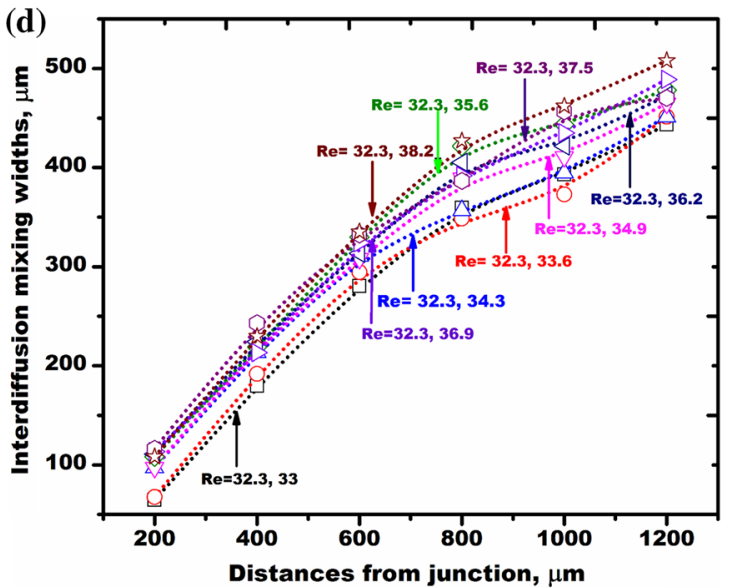

Fig. 5 Comparison of interdiffusion mixing widths at equal Reynolds number flow in both the branches (a), different Reynolds number flow in both the branches $(\mathbf{b}), \operatorname{Re}_{\text {Dye }}=6.0$ with different $\operatorname{Re}_{\text {Water }}(\mathbf{c}), \operatorname{Re}_{\text {Dye }}=32.3$ with different $\operatorname{Re}_{\text {Water }}(\mathbf{d})$ 